\title{
Study the role of serum cartilage oligomericmatrix protein (COMP) in the diagnosis of rheumatoid arthritis patients
}

\author{
Mohammad A. Sweilam ${ }^{1}$, Mohammad A. Attia ${ }^{1}$, Hanan M. El-Saadany ${ }^{2}$, \\ Asmaa S. Ibrahim ${ }^{*}$
}

Departments of ${ }^{1}$ Clinical Pathology and ${ }^{2}$ Physical Medicine, Rheumatology \& Rehabilitation Faculty of Medicine - Tanta University

*Corresponding author:Asmaa S. Ibrahim; Mobile: 01002558308; Email:smsma_smsm1988@outlook.com

\begin{abstract}
Background: rheumatoid arthritis (RA) is a systemic autoimmune disease of unknown etiology. Cartilage oligomeric matrix protein (COMP) is one of markers used for early predicting joint destruction and disease activity in RA disease. Objective: in the present study we evaluated the role of COMP as diagnostic marker in RA patients in comparison with other traditional markers and its correlation with disease activity parameters. Patients and Methods: blood samples were collected from 50 patients newly diagnosed with rheumatoid arthritis (Group I) and also from 30 healthy subjectsas a control group (Group II).Serum level of COMP was measured by enzyme-linked immunosorbent assay (ELISA). Results: there was a high significant difference between the RA patients group and the control group regardingserum COMP level.Also, there was a significant correlation between serum COMP level with clinical and laboratory data of active RA patients.Conclusions: serum COMP could be useful for early diagnosis of rheumatoid arthritis and also could be used as a marker of disease activity and joint destruction.
\end{abstract}

Keywords: serum cartilage oligomeric matrix protein, rheumatoid arthritis

\section{Introduction}

Rheumatoid arthritis (RA) is a chronic inflammatory disease that influence from $0.5 \%$ to $1 \%$ of population, so it believed to be the most common chronic inflammatory autoimmune disease. It often occurs at 50 years of age, women are influenced from three to four times more than men ${ }^{(1)}$.

Rheumatoid arthritis is characterized by pain in several joints and destruction of bone and cartilage in joints. Also, it can result in disability and loss of joint function ${ }^{(2)}$.

Rheumatoid arthritis is also characterized by multiple extra articular manifestations such as: nodules, muscle weakness, nervous system, vasculitis, hematological abnormalities, skin disease e.g. neutrophil dermatitis, ocular, lung, cardiac and other organs could be involved, which influencing a small percentage of the adult persons all over the world ${ }^{(3)}$.

The most important characteristic of rheumatoid arthritis is proliferative and inflammatory synovitis of the peripheral joints which is accompanied by progressed and severe destruction to the articular cartilage and bone that may cause joint distortion and disability ${ }^{(4)}$.

It is very important to start diagnosis and treatment in the early stages of RA, because this may help in slowing down progression of thedisease. The diagnosis and staging of patients with RA is mainly depends on the clinical symptoms, imaging results and some classic laboratory tests such as citrullinated peptides (Anti$\mathrm{CCP}), \mathrm{ESR}, \mathrm{CRP}$ and $\mathrm{RF}^{(\mathbf{5})}$.

Many markers with varied specificity have been discovered each day to aid in diagnosis and prognosis of rheumatoid arthritis in the early stage. Cartilage oligomeric matrix protein (COMP) is a novel marker of cartilage degradation which was detected in the synovial fluid and serum of patients with rheumatoid arthritis ${ }^{(6)}$.

COMP is a non-collagenous matrix protein and it is a member of the thrombospondin glycoprotein family, mainly expressed in cartilage and also in tendon and biological fluids including synovial fluid and serum in patients with 
RA and other diseases such as osteoarthritis (7).

COMP is a $524 \mathrm{kDa}$, extracellular protein which is found in the cartilage, normal ligaments, menisci and tendons ${ }^{(8)}$. COMP can stimulate the complement system, interact with other proteins to preserve cartilage integrity and adjust chondrocyte function and cell dispersion. COMP also may aid in control cartilage damage, follow up and defining therapeutic response ${ }^{(3)}$.

The role of COMP in diagnosis and prognosis of rheumatoid arthritis is controversial, some reports has concluded that it has the potential to be a useful diagnostic and prognostic marker of the disease severity and the response to treatment in cases of rheumatoid arthritis ${ }^{(\mathbf{1 , 8})}$. On the other hand, there are contradictory studies about its usefulness in diagnosis and predicting the severity of the disease ${ }^{(\mathbf{9})}$.

\section{Aim of the work}

The aim of the present study is to evaluate the role of serum cartilage oligomeric matrix protein (COMP) as diagnostic marker in rheumatoid arthritis patients in comparison with other traditional markers (rheumatoid factor and anti-cyclic citrullinated peptide antibody levels) and its correlation with disease activity parameters.

\section{Patients and Methods \\ Patients:}

This case-control study included 50 patients fulfilling the ACR/EULAR classification of rheumatoid arthritis ${ }^{(\mathbf{1 0})}$. They were selected from Rheumatology Outpatient Clinic and Internal Medicine and Rheumatology Department at Tanta University Hospital. All patients gave consent for participation in this study.

Thirty apparently healthy volunteers served as a control group. They are matched for age and sex with the RA group.

\section{Inclusion criteria:}

- Confirmed newly diagnosed patients with rheumatoid arthritis according to ACR/EULAR

(2016)
Classification Criteria for Rheumatoid Arthritis (10).

- More than 18 years.

- Agree to participate in the study.

- Lack of osteoarthritis or any other inflammatory articular diseases.

\section{Exclusion criteria:}

- Patient with rheumatic arthritis, osteoarthritis.

- Patient with gouty arthritis.

- Did not agree to participate.

- Patients suffered from other severe diseases and could not participate in the study.

- Patients with congenital disorders.

Methods:

- Patients under therapy.

\section{I-History taking:}

All participating patients were subjected to the following:

1. Detailed history taking with special emphasis on: age, sex, disease duration, drugs taken (steroids, NSAID and DMARDs), the duration of morning stiffness, joint tenderness, joint swelling, menstrual history, history of smoking, alcohol consumption and presence of other diseases.

2. Present history: a full history of the present illness was taken from each patient.

3. Past history: history of similar condition in the family.

\section{II-General examination:}

1. Systemic examination and local examination of locomotor system were done with special stress on the affected joints.

2. Full clinical examinationincluding musculoskeletal examination.

3. Disease activity was assessed by the modified Disease Activity Score 28 (DAS 28CRP) ${ }^{(11)}$.

Assessment of RA disease activity score was done by reporting each of swollen joint count (SJC) (0-28), tender joint count (TJC) (0-28) and CRP for all our patients and the patient global health assessment $(\mathrm{GH})$ is measured as reported in cm on visual analog scale (VAS) (from $0=$ best to $100=$ worst) recording them 
in a special DAS28-CRP score calculator that uses the following formula: DAS28-CRP = $[0.56 *$ sqrt $(\mathrm{TJC} 28)+0.28 *$ sqrt $(\mathrm{SJC} 28)+$ $\left.0.36^{*} \ln (\mathrm{CRP}+1)\right]+0.014^{*} \mathrm{GH}+0.96$. Where sqrt: square root.

\section{Interpretation:}

$1-\leq 2.6 \ldots \ldots \ldots \ldots \ldots$ Remission.

$2-2.6$ - $\leq 3.2 \ldots \ldots \ldots$... Low

disease activity.

3-3.2 to $\leq 5.1$......... Moderate

disease activity.

4- > 5.1............... High

disease activity.

\section{III-Laboratory investigation:}

- Basic laboratory investigation:

1-Complete blood picture by coulter counter $(\mathrm{CBC})^{(\mathbf{1 2})}$.

2- Erythrocyte sedimentation rate (ESR, $\mathrm{mm} / \mathrm{h}$ ) estimated by Wester-gren method ${ }^{(11) .}$

3- C-reactive protein (CRP).

4- Rheumatoid factor (RF).

5- Anti-citrullinated peptide (ACCP).

- Specific laboratory investigation

Serum Cartilage Oligomeric Matrix

Protein (COMP) using ELISA.

\section{Blood sampling:}

Seven ml sample of venous blood were collected from subjects after their concept under aseptic condition by the use of disposable sterile plastic syringe. The sample was distributed as follow:

- $1.6 \mathrm{ml}$ blood sample added to $0.4 \mathrm{ml}$ sodium citrate in test tube for erythrocyte sedimentation rate (ESR) blood test.

- $1 \mathrm{ml}$ blood sample collected for complete blood picture using tube containing $50 \mu$ lethylenediamine tetra acetic acid (EDTA) (10\% conc.) as invitro anticoagulant.

- The remaining part was put in a dry clean centrifuge tube and allowed to clot for 30 minutes at 5000 r.p.m for separation of the serum for estimation the following:

-Rheumatoid factor with titre (RF $\mathrm{IgM}, \mathrm{IU} / \mathrm{mL}$ ) measured by latex agglutination slide for qualitative and semi quantitative determination of RF in serum ${ }^{(13)}$.

-CRP with titre measured by latex agglutination test. Elevated CRP > 6 $\mathrm{mg} / \mathrm{L}$ ) lead to visible agglutination of latex particles ${ }^{(\mathbf{1 4})}$.

-Anti-CCP antibodies with titre were measured by enzyme-linked immunosorbent assay (ELISA) ${ }^{(13)}$.

\section{Principle of the Human (COMP) ELISA} Kit assay:

The kit used a double-antibody sandwich enzyme-linked immunosorbent assay (ELISA) to assay the level of Human cartilage oligomeric matrix protein (COMP) in samples. First, we add (COMP) to monoclonal antibody enzyme wellwhich is pre-coated with Human cartilage oligomeric matrix protein (COMP) monoclonal antibody. After incubation, cartilage oligomeric matrix protein (COMP) antibodies labeled with biotin was added and combined with StreptavidinHRP to form immune complex, then incubated and washed again to remove the uncombined enzyme. Then Chromogen solutions A, B were added, the color of the liquid changed into the blue, and at the effect of acid, the color finally became yellow. The chroma of color and the concentration of the human substance COMP of sample were positively correlated.

All components refrigerated at $2-8^{\circ} \mathrm{C}$ environment, the kit should be balanced 30 minutes in the ambient temperature before use. If the coated plates of Enzyme haven't been used up after opened, the remaining plates should be stored in sealed bag.

\section{Samples preparation:}

Samples were stored at $-20^{\circ} \mathrm{C}$ until analyzed. Icteric, lipemic or hemolysed samples were excluded as they may give erroneous results. Samples were mixed well before assaying.

\section{Assay procedure:}

All calibrators, controls and samples were tested in duplicate. All solutions were allowed to reach room temperature before use. 


\section{Standard dilution:}

The kit supplied one original standard reagent, so it was diluted according to the instruction.

\begin{tabular}{|c|c|c|}
\hline 48ng/mL & $\begin{array}{l}\text { Standard } \\
\text { No.5 }\end{array}$ & $\begin{array}{l}120 \mu l \text { Original } \\
\text { Standard }+120 \mu l \\
\text { Standard diluent } \\
\end{array}$ \\
\hline $24 \mathrm{ng} / \mathrm{mL}$ & $\begin{array}{l}\text { Standard } \\
\text { No.4 }\end{array}$ & 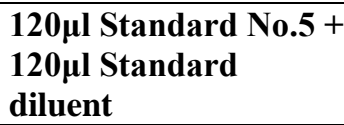 \\
\hline $12 \mathrm{ng} / \mathrm{mL}$ & $\begin{array}{l}\text { Standard } \\
\text { No.3 }\end{array}$ & 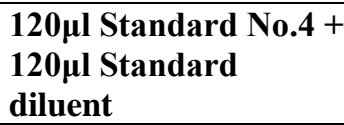 \\
\hline 6ng/mL & $\begin{array}{l}\text { Standard } \\
\text { No.2 }\end{array}$ & 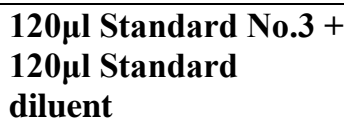 \\
\hline 3ng/mL & $\begin{array}{l}\text { Standard } \\
\text { No.1 }\end{array}$ & 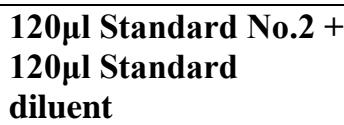 \\
\hline
\end{tabular}

2. The quantity of the plates depends on the quantities of to be tested samples and the standards. So, each standard and blank well might be duplicated. Every sample shall be made according to the required quantity.

\section{Inject samples:}

(1)Blank well: samples and COMPantibody labeled with biotin, Streptavidin-HRP shouldn't be added, only Chromogen solution A and B, and stop solution were allowed; other operations were the same.

(2)Standard wells:standard 50 Streptavidin-HRP 50 $\mu$ lwere added.

(3)To be test wells:sample $40 \mu \mathrm{l}$ was added, and then both COMPantibody $10 \mu 1$ and Streptavidin-HRP $50 \mu \mathrm{l}$ were added. Then, the sealing memberance was sealed, and it was gently shaken and then incubated 60 minutes at $37^{\circ} \mathrm{C}$.

4. Confection: then diluted 30 times, the $30 \times$ washing concentrate with distilled water as standby.

5. Washing: the memberance carefully removed and the liquid was drained, the remaining water was shaken away.

6.Chromogen solution A: $50 \mu \mathrm{l}$ was added and then chromogen solution B: $50 \mu \mathrm{l}$ was added to each well. Gently mixed, incubated for $10 \mathrm{~min}$ at $37^{\circ} \mathrm{C}$ away from light.
7. Stop solution: $50 \mu 1$ was added into each well to stop the reaction (theblue changes into yellow immediately).

8. Final measurement: blank well was taken as zero; the optical density (OD) was measured under $450 \mathrm{~nm}$ wavelength which should be carried out within $15 \mathrm{~min}$ after adding the stop solution.

9. According to standards'concentration and the corresponding OD values, the standard curve linear regression equation was calculated out and then the OD values of the sample on the regression equation was applied to calculate the corresponding sample's concentration. It is acceptable to use kinds of software to make calculations.

\section{Calculation of results:}

The standard density was taken as the horizontal, the OD value for the vertical. The standard curve was drawn on graph paper, the corresponding density was found out according to the sample OD value by the sample curve (the result is the sample density) or calculated the straight line regression equation of the standard curve with the standard density and the OD value, with the sample OD value in the equation, the sample density was calculated. Normal range: $0.3-22.6 \mathrm{ng} / \mathrm{ml}$.

\section{Statistical analysis}

Statistical presentation and analysis of the present study was conducted by using the mean, standard deviation, standard error, Linear Correlation Coefficient test, unpaired student t- test, Chi-square and ROC curve.

Sensitivity: Probability that the test results will be positive when the disease is present (true positive rate, expressed as a percentage).

Specificity: Probability that the test results will be negative when the disease is absent (true negative rate, expressed as a percentage).

Accuracy: The ratio of the true positive and true negative on all patients. 
NPV: Negative Predictive value (the probability of not having the disease when the test result is negative).

PPV: Positive Predictive value (the probability of disease in an individual with a positive test result).

\section{Results}

Table (2) demonstrates the ages of rheumatoid arthritis patients of group I ranged from 32 to 55 years old with mean value $46.920 \pm 5.721$ years and the age of group II (control group) ranged from 33 to 56 years old with mean value $45.167 \pm 8.137$ years.In comparing the age of the studied groups, there was no significant differences between group I and group II $(\mathrm{P}=0.262)$.It also demonstrates the sex of the studied groups. They were ten males and forty females in group I, four males and twenty six females in group II (control group). There was no significant differences between two groups $(\mathrm{P}=0.447)$.

Table (2): Age (Years) and sex in studied groups.

\begin{tabular}{|c|c|c|c|c|c|c|c|c|}
\hline \multirow[t]{2}{*}{ Age (Years) } & \multicolumn{6}{|c|}{ Groups } & \multicolumn{2}{|c|}{ T-Test } \\
\hline & \multicolumn{3}{|c|}{ RA patients } & & \multicolumn{2}{|c|}{ Controls } & $\mathbf{t}$ & P-value \\
\hline Range & \multirow{2}{*}{\multicolumn{3}{|c|}{$\frac{32-55}{46.920 \pm 5.721}$}} & & \multicolumn{2}{|c|}{$33-56$} & \multirow[t]{2}{*}{1.130} & \multirow[t]{2}{*}{0.262} \\
\hline Mean \pm SD & & & & & 45.10 & & & \\
\hline \multirow[t]{3}{*}{ Sex } & \multicolumn{6}{|c|}{ Groups } & \multirow{2}{*}{\multicolumn{2}{|c|}{ Chi-Square }} \\
\hline & \multicolumn{2}{|c|}{ RA patients } & \multicolumn{2}{|c|}{ Controls } & \multicolumn{2}{|c|}{ Total } & & \\
\hline & $\mathbf{N}$ & $\%$ & $\mathbf{N}$ & $\%$ & $\mathbf{N}$ & $\%$ & $\mathbf{X}^{2}$ & P-value \\
\hline Male & 10 & 20.00 & 4 & 13.33 & 14 & 17.50 & \multirow[t]{3}{*}{0.577} & \multirow[t]{3}{*}{0.447} \\
\hline Female & 40 & 80.00 & 26 & 86.67 & 66 & 82.50 & & \\
\hline Total & 50 & 100.00 & 30 & 100.00 & 80 & 100.00 & & \\
\hline
\end{tabular}

Table (3) demonstrates the serum COMP levels in the studied groups ( $\mathrm{ng} / \mathrm{ml})$ : In group I serum COMP ranged from (4.5 $50.3) \mathrm{ng} / \mathrm{ml}$ with mean value $28.222 \pm$ $10.663 \mathrm{ng} / \mathrm{ml}$, in group II (control group) ranged from $(8.1-28.3) \mathrm{ng} / \mathrm{ml}$ with mean value $17.017 \pm 5.694 \mathrm{ng} / \mathrm{ml}$. There was a significant elevation of serum COMP levels in group I compared to group II ( $\mathrm{P}<$ 0.001).Italso demonstrates the serum Anti-
CCP levels in the studied groups: In group I serum Anti-CCP ranged from (9.8 - 222.9) $\mathrm{U} / \mathrm{ml}$ with mean value $57.528 \pm$ $46.473 \mathrm{U} / \mathrm{ml}$. In group II (control group) ranged from $(4.3$ - 101) $\mathrm{U} / \mathrm{ml}$ with mean value $29.770 \pm 25.077 \mathrm{U} / \mathrm{ml}$. There was a significant elevation of serum Anti-CCP levels in group I compared to group II ( $\mathrm{P}=$ 0.003 ).

Table (3): Statistical analysis of serum COMP level (ng/ml) and Anti-CCP level (U/ml) in group I and group II (control group)

\begin{tabular}{|c|c|c|c|c|}
\hline \multirow{2}{*}{ COMP (ng/ml) } & \multicolumn{2}{|c|}{ Groups } & \multicolumn{2}{|c|}{ T-Test } \\
\hline & RA patients & Controls & $\mathbf{t}$ & P-value \\
\hline Range & \multirow{2}{*}{$\begin{array}{c}4.5-50.3 \\
28.222 \pm 10.663\end{array}$} & $8.1-28.3$ & \multirow[t]{2}{*}{5.311} & \multirow[t]{2}{*}{$<0.001 *$} \\
\hline Mean \pm SD & & $17.017 \pm 5.694$ & & \\
\hline \multirow[t]{2}{*}{ Anti-CCP (U/ml) } & \multicolumn{2}{|c|}{ Groups } & \multicolumn{2}{|c|}{ T-Test } \\
\hline & RA patients & Controls & $\mathbf{t}$ & P-value \\
\hline Range & $9.8-222.9$ & $4.3-101$ & 3.014 & $0.003 *$ \\
\hline Mean \pm SD & $57.528 \pm 46.473$ & $29.770 \pm 25.077$ & & \\
\hline
\end{tabular}

Table (4) demonstrates the ESR levels in the studied groups $(\mathrm{mm} / 1 \mathrm{~h})$ : In group I ESR ranged from $(12-95) \mathrm{mm} / 1 \mathrm{~h}$ with mean value $41.880 \pm 13.008 \mathrm{~mm} / 1 \mathrm{~h}$, in group II (control group) ranged from (2 -
8) $\mathrm{mm} / 1 \mathrm{~h}$ with mean value $5.133 \pm 1.995$ $\mathrm{mm} / 1 \mathrm{~h}$. In comparing the studied groups, there was a significant elevation of ESR levels in group I compared to group II $(\mathrm{P}<$ 0.001).

Table (4):Statistical analysis of ESR in group I compared to group II(control group) 
Study the role of serum cartilage oligomericmatrix protein (COMP) in the diagnosis of rheumatoid...

\begin{tabular}{|c|c|c|c|c|}
\hline \multirow{2}{*}{ ESR (mm/1h) } & \multicolumn{2}{|c|}{ Groups } & \multicolumn{2}{c|}{ T-Test } \\
\cline { 2 - 4 } & RA patients & Controls & P-value \\
\hline Range & $12-95$ & $2-8$ & 5.327 & $<0.001^{*}$ \\
\hline Mean \pm SD & $41.880 \pm 13.008$ & $5.133 \pm 1.995$ & & \\
\hline
\end{tabular}

Table (5) demonstrates the serum CRP levels in the studied groups (mg/L): In group I serum CRP ranged from (6 - 48) $\mathrm{mg} / \mathrm{L}$ with mean value $20.336 \pm 14.033$ $\mathrm{mg} / \mathrm{L}$, in group II (control group) ranged from $(1-6) \mathrm{mg} / \mathrm{L}$ with mean value $3.580 \pm$ $1.385 \mathrm{mg} / \mathrm{L}$. There was a significant elevation of serum CRP levels in group I compared to group II $(\mathrm{P}<0.001)$. It also demonstrates the serum RF levels in the studied groups (IU/ml): In group I serum $\mathrm{RF}$ ranged from (48 - 190) IU/ml with mean value $114.900 \pm 35.477 \mathrm{IU} / \mathrm{ml}$, in group II (control group) ranged from $(1-6) \mathrm{mg} / \mathrm{dl}$ with mean value $2.533 \pm 1.252 \mathrm{IU} / \mathrm{ml}$. There was a significant elevation of serum $\mathrm{RF}$ levels in group I compared to group II $(\mathrm{P}<0.001)$.

Table (5): Statistical analysis of serum CRP level (mg/L) and RF level (IU/ml) in group I and group II (control group)

\begin{tabular}{|c|c|c|c|c|}
\hline \multirow{2}{*}{ CRP (mg/L) } & \multicolumn{2}{|c|}{ Groups } & \multicolumn{2}{c|}{ T-Test } \\
\cline { 2 - 5 } & RA patients & Controls & t & P-value \\
\hline Range & $6-48$ & $1-6$ & 6.504 & $<0.001^{*}$ \\
\hline Mean \pm SD & $20.336 \pm 14.033 \quad$ Groups & $3.580 \pm 1.385$ & \multicolumn{2}{c|}{ T-Test } \\
\hline RF (IU/ml) & \multicolumn{2}{|c|}{ Controls } & 17.297 & P-value \\
\cline { 2 - 4 } & RA patients & $1-6$ & & \\
\hline Range & $48-190$ & $2.533 \pm 1.252$ & \\
\hline Mean \pm SD & $114.900 \pm 35.477$ & & \\
\hline
\end{tabular}

Table (6) demonstrates the $\mathrm{Hb}$ levels in the studied groups $(\mathrm{g} / \mathrm{dl})$ : In group I Hb level ranged from $(8-12) \mathrm{g} / \mathrm{dl}$ with mean value $10.066 \pm 0.933 \mathrm{~g} / \mathrm{dl}$, in group II (control group) ranged from $(12-14.5) \mathrm{g} / \mathrm{dl}$ with mean value $12.850 \pm 0.756 \mathrm{~g} / \mathrm{dl}$. There was a significant decrease of $\mathrm{Hb}$ levels in group I compared to group II $(\mathrm{P}<0.001)$.

Table (6): Statistical analysis of $\mathrm{Hb}$ level (g/dl) in group I and group II (control group)

\begin{tabular}{|c|c|c|c|c|}
\hline \multirow{2}{*}{ Hb$(\mathbf{g} / \mathbf{d l})$} & \multicolumn{2}{|c|}{ Groups } & \multicolumn{2}{c|}{ T-Test } \\
\cline { 2 - 4 } & RA patients & Controls & P-value \\
\hline Range & $8-12$ & $12-14.5$ & -13.839 & $<0.001^{*}$ \\
\hline Mean \pm SD & $10.066 \pm 0.933$ & $12.850 \pm 0.756$ & \\
\hline
\end{tabular}

Table (7) demonstrates the platelets levels in the studied groups, in group I serum platelets ranged from $(160$ - 460) $\mathrm{x}$ $10^{9} /$ Liter with mean value $211.480 \pm$ $61.660 \times 10^{9} / \mathrm{L}$, in group II (control group) ranged from $(150-400) \times 10^{9} / \mathrm{L}$ with mean value $200.400 \pm 52.470 \times 10^{9} / \mathrm{L}$. There was no significant differences between group I and group II $(\mathrm{P}=0.414)$. It also demonstrate the WBCs levels in the studied groups $\times 10^{9} / \mathrm{L}$, In group I WBCs ranged from $(4-13.7) \times 10^{9} / \mathrm{L}$ with mean value $6.939 \pm 2.138 \times 10^{9} / \mathrm{L}$, in group II (control group) ranged from $(4.9-11) \times 10^{9} / \mathrm{L}$ with mean value $6.577 \pm 1.423 \times 10^{9} / \mathrm{L}$. There was no significant differences between group I and group II $(\mathrm{P}=0.412)$.

Table (7): Statistical analysis of Platelets levels $\times 10^{9} / \mathrm{L}$ and WBCs levels $\times 10^{9} / \mathrm{L}$ in group I and group II (control group)

\begin{tabular}{|c|c|c|}
\hline Platelets & Groups & T-Test \\
\hline
\end{tabular}




\begin{tabular}{|c|c|c|c|c|}
\hline $\mathbf{x 1 0} / \mathbf{L}$ & RA patients & Controls & t & P-value \\
\hline Range & $160-460$ & $150-400$ & 0.821 & 0.414 \\
\hline Mean \pm SD & $211.480 \pm 61.660$ & $200.400 \pm 52.470$ & \multicolumn{2}{|c|}{ T-Test } \\
\hline \multirow{2}{*}{ WBCsx10 $1 / \mathbf{L}$} & \multicolumn{2}{|c|}{ Groups } & t & P-value \\
\cline { 2 - 3 } & RA patients & Controls & 0.824 & 0.412 \\
\hline Range & $4-13.7$ & $4.9-11$ & & \\
\hline Mean \pm SD & $6.939 \pm 2.138$ & $6.577 \pm 1.423$ & \\
\hline
\end{tabular}

Table (8) demonstrates the modified disease activity score (DAS 28CRP) of rheumatoid arthritis patients (group I) ranged from (2.9 - 7) with mean value $(5.154 \pm 0.923)$. SJC 28 ranged from $(0-21)$ with mean value $(11.660 \pm 5.752)$.
TJC28 ranged from $(0-28)$ with mean value (9.720 \pm 5.987$)$. CRP ranged from (6 $48)$ with mean value $(20.336 \pm 14.033)$. Vas ranged from $(25$ - 70) with mean value $(52.020 \pm 11.821)$.

Table (8): DAS28 CRP in group I RA patients:

\begin{tabular}{|c|c|c|}
\hline \multicolumn{2}{|c|}{ Variant } & RA patients \\
\hline \multirow[t]{2}{*}{ Swollen joints } & Range & $0-21$ \\
\hline & Mean \pm SD & $11.660 \pm 5.752$ \\
\hline \multirow{2}{*}{ Tender joints } & Range & $0-28$ \\
\hline & Mean \pm SD & $9.720 \pm 5.987$ \\
\hline \multirow[t]{2}{*}{ CRP } & Range & $6-48$ \\
\hline & Mean \pm SD & $20.336 \pm 14.033$ \\
\hline \multirow[t]{2}{*}{ VAS (0-100) } & \begin{tabular}{|l|} 
Range \\
\end{tabular} & $25-70$ \\
\hline & Mean \pm SD & $52.020 \pm 11.821$ \\
\hline \multirow[t]{2}{*}{ DAS28 } & Range & $2.9-7$ \\
\hline & Mean \pm SD & $5.154 \pm 0.923$ \\
\hline
\end{tabular}

Table (9) demonstrates the correlation between serum COMP levels and Anti-CCP, Age, ESR, RF, CRP, Hb, Platelets, WBCS.There was no significant correlation between COMP and Age, $\mathrm{Hb}$, Platelets, WBCs but there was a significant correlation between COMP and Anti-CCP, ESR, CRP, RF.

Table (9): Correlation between COMP level and Anti-CCP, Age, ESR, RF, CRP, Hb, Platelets, WBCS

\begin{tabular}{|c|c|c|}
\hline \multicolumn{2}{|c|}{ Correlations } \\
\hline & \multicolumn{2}{|c|}{ COMP (ng/ml) } \\
\cline { 2 - 3 } & $\mathbf{r}$ & P-value \\
\hline Anti-CCP $(\mathbf{U} / \mathbf{m l})$ & 0.430 & $0.002^{*}$ \\
\hline Age (Years) & -0.250 & 0.079 \\
\hline ESR (mm/1h) & 0.913 & $<0.001^{*}$ \\
\hline RF $(\mathbf{I U} / \mathbf{m l})$ & 0.322 & $0.022^{*}$ \\
\hline CRP $(\mathbf{m g} / \mathbf{L})$ & 0.423 & $0.002^{*}$ \\
\hline Hb $(\mathbf{g} / \mathbf{d l})$ & -0.022 & 0.579 \\
\hline Platelets $(\mathbf{x 1 0} / \mathbf{L})$ & -0.091 & 0.481 \\
\hline WBCS $(\mathbf{x 1 0} / \mathbf{L})$ & -0.102 & \\
\hline
\end{tabular}

Table (10) demonstrates the correlation between serum COMP levels and DAS 28. There was a significant positive correlation with DAS28 total score $(\mathrm{P}<0.001)$, also a significant positive correlation with SJC $28 \quad(\mathrm{P}<0.001)$, a significant positive correlation with TJC28 $(\mathrm{P}<0.001)$ and a significant positive correlation with $\mathrm{CRP}(\mathrm{P}=0.002)$ with no significant correlation with VAS $(\mathrm{P}=0.149)$.

Table (10): Correlation of COMP with DAS28CRP

\begin{tabular}{|c|c|c|}
\hline \multirow{2}{*}{} & \multicolumn{2}{|c|}{ COMP } \\
\cline { 2 - 3 } & $\mathbf{R}$ & p-value \\
\hline
\end{tabular}


Study the role of serum cartilage oligomericmatrix protein (COMP) in the diagnosis of rheumatoid...

\begin{tabular}{|l|c|c|}
\hline Swollen joints & 0.979 & $<0.001^{*}$ \\
\hline Tender joints & 0.894 & $<0.001^{*}$ \\
\hline CRP & 0.423 & $0.002^{*}$ \\
\hline VAS (0-100) & 0.207 & 0.149 \\
\hline DAS28 & 0.889 & $<0.001^{*}$ \\
\hline
\end{tabular}

Table (11) demonstrates that at a cut off value of COMP was $>22.6 \mathrm{ng} / \mathrm{ml}$, the sensitivity of COMP was $74 \%$ and the specificity was $83.33 \%$, corresponding to a positive predictive value (PPV) of $88.1 \%$ and a negative predictive value (NPV) of $65.8 \%$ between group I and group II. The receiver-operating characteristics (ROC) curve shows that the accuracy was $82.9 \%$ between group I and II.It also demonstrates that at a cut off value of Anti-CCP was $>37.7 \mathrm{ng} / \mathrm{ml}$, the sensitivity of AntiCCP was $64 \%$ and the specificity was $76.67 \%$, corresponding to a positive predictive value (PPV) of $82.1 \%$ and a negative predictive value (NPV) of $56.1 \%$ between group I and group II. The receiveroperating characteristics (ROC) curve shows that the accuracy was $71.4 \%$ between group I and II.

Table (11): Cut off, Sensitivity, Specificity, PPV, NPV and Accuracy of serum COMP and Anti-CCP between group I and II

\begin{tabular}{|c|c|c|c|c|c|c|}
\hline \multicolumn{7}{|c|}{ ROC curve between Patients and Control } \\
\hline & Cutoff & Sens. & Spec. & PPV & NPV & Accuracy \\
\hline COMP $(\mathbf{n g} / \mathbf{m l})$ & $>22.6$ & $\mathbf{7 4 . 0 0}$ & $\mathbf{8 3 . 3 3}$ & $\mathbf{8 8 . 1}$ & $\mathbf{6 5 . 8}$ & $\mathbf{8 2 . 9 \%}$ \\
\hline \hline Anti-CCP $(\mathbf{U} / \mathbf{m l})$ & $>37.7$ & $\mathbf{6 4 . 0 0}$ & $\mathbf{7 6 . 6 7}$ & $\mathbf{8 2 . 1}$ & $\mathbf{5 6 . 1}$ & $\mathbf{7 1 . 4 \%}$ \\
\hline
\end{tabular}

\section{Discussion}

Rheumatoid arthritis (RA) is a chronic inflammatory disease that influence from $0.5 \%$ to $1 \%$ of population, so it believed the most common chronic inflammatory autoimmune disease. It often occurs at 50 years of age, women are influenced from three to four times more than men. Early diagnosis for RA is very important and it is complex because early presentation of RA patients may confound with other inflammatory arthritis.Moreover, the classical clinical picture of RA tends to present after the advancement of the disease and also, incomplete clinical picture usually exists in the first few months or even years. Additionally, treatment with antiinflammatory drugs or corticosteroids may cover symptoms and signs ${ }^{(\mathbf{1})}$.

It is very important to start diagnosis and treatment in the early stages of RA, because this aids in slowing down advancement of the disease. Recently, the diagnosis and staging of patients with RA is mainly counts on the clinical symptoms, imaging results and some classic laboratory tests ${ }^{(5)}$.

The most characteristic expression of the autoimmune response is the presence of autoantibodies such as citrullinated peptides (Anti-CCP), ESR, CRP and RF, although the association of RF and AntiCCP with the disease activity is not clear yet ${ }^{(15)}$.

Many markers with varied specificity have been discovered each day to aid in early diagnosis and prognosis of rheumatoid arthritis. Cartilage oligomeric matrix protein (COMP) is a novel marker of cartilage degradation which was detected in the synovial fluid and serum of patients with rheumatoid arthritis (6).

COMP is a $435 \mathrm{kDa}$, extracellular protein which is found in the cartilage, normal ligaments, menisci and tendons (8).COMP can stimulate the complement system, interact with other proteins to perservecartilage integrity and control chondrocyte function and cell dispersion. COMP also may aid in control cartilage 
damage, follow up and defining therapeutic response ${ }^{(3)}$.

The cartilage destruction which takes places in the early stage of the disease may stimulate immune reaction in the synovium resulting in specific cellular response in joints which lead to progressive remodeling of the influenced joints explaining chronicity of the disease ${ }^{(16)}$.

In this study we aim to evaluate the role of serum cartilage oligomeric matrix protein (COMP) as diagnostic marker in rheumatoid arthritis patients in comparison with other traditional markers (rheumatoid factor and anti-cyclic citrullinated peptide antibody levels) and its correlation with disease activity parameters.

In the present study was carried out at Tanta University Hospital where we studied newly diagnosed 50 patients with rheumatoid arthritis according to ACR/EULAR ${ }^{(\mathbf{1 0})}$ classification Criteria for RA and 30 healthy subjects as a normal control group. All groups were matched as regard age and sex; $80 \%$ of patients were female.

These results in agreement with these reported by Courvoisier et al. (17) and Benbouazza et al. ${ }^{(18)}$ as females represent $80.3 \%$ of 112 rheumatoid patients and $88.2 \%$ of 51 rheumatoid patients respectively of their studied patients.

In the present study, age in rheumatoid patients was (32-55 years) with mean value $46.920 \pm 5.721$, this agrees with a study reported by Benbouazza et al. (18) who found that the data on the profile of patients with RA in North Africa (Morocco and Egypt) in the Quantitative Standard Monitoring of Patients with RA (QUESTRA) and mentioned that patients in North Africa are younger than patients in other countries which was also reported by Shin et al. (19) study on Korean rheumatoid patients that found the age of rheumatoid patients was (16 - 75yrs).

In the present study, no significant correlation was foundbetween COMP and age of patients this is in concordance with the results from Kawashiri ${ }^{(20)}$ who studied forty five rheumatoid arthritis patients with mean age $55.9 \pm 13.5$ years. On the other hand, this finding in disagreement with Wislowska and Jablonska (21) study of thirty rheumatoid arthritis patientsaged 2080 years.Serum COMP levels and disease activity markers weremeasured in all patients. A positive correlation was foundbetween COMP level and age of RA patients $(\mathrm{P}<0.05)$.

In the current study, there was a statistical significant elevation in serum COMP level in the RA patients group compared to the control group ( $\mathrm{P}<0.001)$. In agreement with Rajalingham et al. ${ }^{(8)}$ who studied 61 RA patients fulfilled the ACR 2010 criteria for RA. All were tested for ESR, CRP and serum COMP. Serum COMP concentrations were significantly elevated in the serum of the RA patients compared to the controls ( $\mathrm{p}=0.001)$.

Clark et al. ${ }^{(22)}$ reported that there was a significant increase in serum COMP level in rheumatoid arthritis patients in comparison with the normal control serum COMP levels whether derived from cartilage or synovium could be representative of local effects occurring in the affected joint.

In this study serum COMP specificity test was $83.33 \%$ and sensitivity test was $74 \%$. Those findings were in concordance with the cross sectional study by Liu et $\boldsymbol{a l} .{ }^{(5)}$ who measured serum COMP, Anti-CCP, CRP, ESR in 82 patientswith RA and 34 healthy control subjects and found COMP specificity test was $88.2 \%$ and sensitivity test was $81.7 \%$. These studies found that serum COMP was specific marker for the cartilage degradation in RA.

In the present study, serum Anti-CCP specificity test was $76.67 \%$ and sensitivity test was $64 \%$. Those findings were in concordance with the study conducted by Sharif et al. ${ }^{(23)}$ who found that the specificity and sensitivity of anti-CCP were $89.1 \%$ and $62.5 \%$ respectively in RA patients group.Also in agreement with Liu et al. ${ }^{(5)}$ 
who found that Anti-CCP specificity was $82.4 \%$ and sensitivity was $61 \%$.

In the current study, a significant positive correlation was found between serum COMP level and serum level of AntiCCP $(\mathrm{P}=0.002)$ which is similar with Lindqvist $\boldsymbol{e t}$ al. ${ }^{(3)}$ who studied 183 patients with early rheumatoid arthritis with mean duration of disease at baseline was $11.1 \pm$ 6.1 months, all were tested for serum COMP, Anti-CCP, CRP, ESR and radiographic changes measured by Larsen score were conducted to all patients. A significant correlation was found between serum COMP and anti-CCP levels.

ESR is one of markers of inflammation which indicates the disease activity in RA patients. In the present study ESR was high in RA patients group compared to healthy controls group $(\mathrm{P}<$ 0.001) in agreement Ranganath et al. (24) reported that ESR is one of laboratory indicators of the disease activity in RA patients.

In the present study, a significant positive correlation was found between serum COMP level and ESR ( $\mathrm{P}<0.001)$. These results agree with those of Kawashiri ${ }^{(20)}$ and Aref and Ahmed ${ }^{(\mathbf{1})}$ who found significant positivecorrelation between serum COMP level and ESR and also agree withWislowska and Jablonska (21) who reported that there was significant correlation between ESR and serum COMP levels in RA patients and the increase of these markers facilitate separation of patients with aggressive disease who have rapidly developing destructive changes in small joints.

CRP is another marker of inflammation which helps in evaluation the condition of rheumatoid arthritis. In the current study, there was a significant increase in CRP level in RA patient compared to healthy controls in agreement with Wislowska and Jablonska ${ }^{(21)}$ who found that there was a high level of CRP during the activity of rheumatoid arthritis disease.
In the current study, a positive correlation between serum COMP level and CRP $(\mathrm{P}=0.002)$ which is in concordance with Kawashiri ${ }^{(20)}$;Aref and Ahmed ${ }^{(1)}$ where a significant correlation between serum COMP level and CRP level ( $\mathrm{P}<$ 0.05 ) was found in those studies.

In the present study, there was a positive significant correlation between serum COMP level and RF in agreement with Marti et al. ${ }^{(25)}$ who found that the RF considered as a laboratory activity marker in RA patients correlates with COMP marker in a significant way. But these results in disagreement with that of Wislowska and Jablonska ${ }^{(21)}$ who found that there was no significant correlation between serum COMP level and rheumatoid factor because most of RA patients are seropositives.

In the present study, most of RA patients show anaemia as there is a significant decrease in hemoglobin level. This finding in agreement with Tazi et al. (26) who revealed that anaemia was present in $28.8 \%$ of rheumatoid arthritis patients.

There was no significant correlation between serum COMP level and hemoglobin level, white blood cell count or platelet count in agreement with that found by Wislowska and Jablonska ${ }^{(21)}$ study.

In the present study we found significant positive correlation between COMP level and DAS28 total score $(\mathrm{P}<$ 0.001 ), also a high significant positive correlation was found between serum COMP and SJC28 $(\mathrm{P}<0.001)$ and a significant positive correlation was detected between serum COMP and TJC28 $(\mathrm{P}<0.001)$ in accordance with Kawashiri ${ }^{(20)}$ who found a correlation between serum COMP and DAS28 score was significant ( $\mathrm{P}$ $<0.05)$ and also Wislowska and Jablonska ${ }^{(21)}$ who found a high significant positive correlation of serum COMP and the disease activity DAS 28 score. Wislowska and Jablonska ${ }^{(21)}$ found that increased activity is associated with increase in COMP levels in the serum suggesting that COMP should be 
considered as a marker of disease activity. Also, in agreement with Rajalingham et al. (8) study which found that serum COMP levels was correlated significantly with disease activity based on DAS 28 ( $\mathrm{p}=$ 0.028).

In the current study, we concluded that the serum COMP level could be valuable in the early diagnosis of RA by comparing it with anti-cyclic citrullinated peptide antibody (Anti-CCP) level as these markers appear in the serum in the early stage of the disease which supported by Lindqvist et al., ${ }^{(3)}$ who reported that the serum COMP levels and Anti-CCP increase early in the course of rheumatoid arthritis and also COMPis a potential marker of changes in cartilage turnover.Also, in agreement with Aref and Ahmed ${ }^{(1)}$ who concluded that Anti-CCP is not the sole specific marker for RA patients as the addition of COMP can enhance the diagnosis in the early course of the disease.

The present study found that although the anti-CCP level was significantly high in newly diagnosed RA patients, its predictive accuracy was not as high as that determined for COMPwhich supported by Liu et al., ${ }^{(5)}$ whofound that serum COMP level have a high level of accuracy than serum Anti-CCP level in RA patients.

It is also found in the present study that serum COMP level is positively correlated with various disease activity parameters (CRP, ESR, DAS28 score). These findings were similar to Kawashiri (20) who concluded that serum COMP at baseline reflects clinical disease activity of RA. And also Andersson et al. ${ }^{(7)}$ that found higher serum COMP levels at baseline is a prediction of destructive process in joints of rheumatoid arthritis and concluded that COMP is considered a biomarker of disease activity and cartilage degradation.

\section{Conclusion}

- Serum COMP could be useful for early diagnosis of rheumatoid arthritis by comparing it with anti-cyclic citrullinated peptide antibody (Anti-CCP) serum level as these markers appear in the serum in the early stage of the disease. Also, serum COMP levels have a statistically significant correlation with serum AntiCCP levels in RA patients which predicts aggressive form of the disease as well as a significant correlation with serum ESR, CRP levels and disease activity measured by DAS28 CRP in rheumatoid arthritis patients. Therefore, COMP could be used also as a marker of disease activity and joint destruction.

\section{References:}

1. Aref $M$ and Ahmed $H$ (2015): Cartilage Oligomeric Matrix Protein as New Marker in Diagnosis of Rheumatoid Arthritis. Mod Chem appl., 3 (151), 2.

2. Sokka T, Kautiainen H, Toloza $S$ et al. (2007): quantitative clinical assessment of patients with rheumatoid arthritis seen in standard rheumatology care in 15 countries. Ann Rheum Dis., 66: 1491-1496.

3. Massoud $S$, Mandana $K$, Nayyereh $S$ et al. (2017): Relationship between cartilage oligomeric matrix protein (COMP) and rheumatoid arthritis severity. Electron Physician, 9(12):5940-5947.

4. Wasserman A (2011): Diagnosis and management of rheumatoid arthritis. AmFam Physician, 11: 1245-1252.

5. Liu $\mathrm{F}$, Wang $\mathrm{X}$, Zhang $\mathrm{X}$ et al. (2016): Role of Serum cartilage oligomeric matrix protein (COMP) in the diagnosis of rheumatoid arthritis (RA). Journal of International Medical Research, 44(4): 940-949.

6. Ardle A, Flatley B, Pennington SR et al. (2015): Early biomarkers of joint damage in rheumatoid and psoriatic arthritis. Arthritis Res Ther.,1,17:141.

7. Andersson ML, Svensson B, Petersson IF et al. (2013): Early increase in serum-COMP is associated withjoint damage progression over the first five years in patients with rheumatoid arthritis. BMC musculoskeletal disorders, 14 (1):229. 
8. Rajalingham S, Shamala Rajalingam, Heselynn $\mathrm{H}$ et al. (2017): Cartilage oligomeric matrix protein (COMP) in rheumatoid arthritis and its correlation with sonographic knee cartilage thickness and disease activity. ClinRheumatol., 36:26832688.

9. Bender AL, Da Silveira IG, von Muhlen CA et al. (2010): High specificity but low sensitivity ofcartilage oligomeric matrix protein (COMP) test in rheumatoid arthritis and osteoarthritis. ClinChemLab.Med., 48 (4): 569-570.

10. Salehi-Abari I (2016): 2016 ACR/EULAR Revised Criteria for too Early Diagnosis of Rheumatoid Arthritis. Autoimmune Dis. Ther.Approaches , 3:120.

11. Farheen $K$ and Agarwal SK (2011): Assessment of Disease Activity and Treatment Outcomes in Rheumatoid Arthritis, J Manag Care Pharm., 17: S09-S13.

12. Britten $E$, Brecher $G$ and Johnson $C$ (1969):Evaluation of the coulter counter model S. Am J of clin Pathology, 52:679.

13. Willemze A, Trouw LA, Toes RE and Huizinga TW (2012): The influence of ACPA status and characteristics onthe course of RA. Nature Reviews Rheumatology, 8(3): 144-152.

14. Dixon JS (1984): CRP in the serial assessment of disease activity in RA.Scand. J. Rheumatol., 13: 39-44.

15. Aletaha D, Alasti $F$ and Smolen $J$ (2015):Rheum- atoid factor, not antibodies against citrullinated proteins, is associated with baseline disease activity in rheumatoid arthritis clinical trials. Aletaha et al. Arthritis Research \& Therapy, 17:229.

16. Pap T and Korb-Pap A (2015): Cartilage damage in osteoarthritis and rheumatoid arthritis [mdash] two unequal siblings. Nature Reviews Rheumatology. https://www.ncbi.nlm.nih.gov/pubmed 126195338.

17. Courvoisier N, Dougados $M$, Cantagrel A et al. (2008): Prognostic factors of 10-year radiographic outcome in early rheumatoid arthritis: a prospectivestudy. Arthritis Research and Therapy, 10(5): R106.

18. Benbouazza $K$, Benchekroun $B$, Rkain H et al. (2011): Profile and course of early rheumatoid arthritis inMorocco: a two-year follow-up study. BMCmusculoskeletal disorders, 12 (1), 266.

19. Shin YS, Choi JH, Nahm DH et al. (2005): Rheumatoid Factor is a Marker ofDisease Severity in Korean Rheumatoid Arthritis.Yonsei Medical Journal, 46: 464 - 470.

20. Kawashiri SY, Kawakami A, Ueki Y et al. (2010): Decrement of serum cartilage oligomeric matrix protein (COMP) in rheumatoid arthritis (RA) patients achieving remission after 6 months of etanercept treatment: comparison with CRP, IgM-RF, MMP3 and anti-CCP Ab. Joint Bone Spine, 77(5): 418-420.

21. Wislowska $M$ and Jablonska $B$ (2005): Serum cartilage oligomeric matrix protein (COMP) in rheumatoid arthritis and knee osteoarthritis. ClinRheumatol., 24: 278-284.

22. Clark AG, Jordan JM, Vilim V et al. (1999): Serum cartilage oligomeric matrix protein reflects rheumatoid arthritis presence and severity. Rheum. 42: 2356-2364.

23. Sharif S, Gharibdoost F, Kbarian MA et al. (2007): Comparative study of anti-CCP and RF for the diagnosis of rheumatoid arthritis. Aplar J. Rheumatol., 10: 121-4.

24. Ranganath VK, Khanna $D$ and Paulus HE (2006): ACR remission criteria and response criteria. Clin Exp Rheumatol., 24 (43): S014-21.

25. Marti C, Neidhart M, Gerber T et al. (1999): Cartilage oligomeric matrix protein (COMP): the role of non- 
collagenous cartilage matrix protein as a marker of disease activity and joint destruction in RA and OS patients. Z. Rheumatol., 58: 79-87.

26. Tazi lachhab Hajar, Samira Rostom, Asmae Hari et al. (2015): Prevalence of Anemia and its Association with Parameters of Rheumatoid Arthritis Patients: A Study from the Moroccan Quest - RA Data. J Palliat Care Med., 5:221. 